\title{
Intravenous administration of mesenchymal stem cells prevents angiotensin II-induced aortic aneurysm formation in apolipoprotein E-deficient mouse
}

\author{
Xian-ming Fu ${ }^{\dagger}$, Aika Yamawaki-Ogata ${ }^{\dagger}$, Hideki Oshima, Yuichi Ueda, Akihiko Usui and Yuji Narita*
}

\begin{abstract}
Background: Mesenchymal stem cells (MSCs) are known to be capable of suppressing inflammatory responses. We previously reported that intra-abdominal implantation of bone marrow-derived MSCs (BM-MSCs) sheet by laparotomy attenuated angiotensin II (AngII)-induced aortic aneurysm (AA) growth in apolipoprotein E-deficient $\left(\mathrm{apoE}^{-/-}\right)$mice through anti-inflammation effects. However, cell delivery by laparotomy is invasive; we here demonstrated the effects of multiple intravenous administrations of BM-MSCs on Angll-induced AA formation.

Methods: BM-MSCs were isolated from femurs and tibiae of male $\mathrm{apoE}^{-/-}$mice. Experimental AA was induced by Angll infusion for 28 days in apoE ${ }^{-/-}$mice. Mice received weekly intravenous administration of BM-MSCs $(n=12)$ or saline $(n=10)$. After 4 weeks, AA formation incidence, aortic diameter, macrophage accumulation, matrix metalloproteinase (MMP)' activity, elastin content, and cytokines were evaluated.

Results: Angll induced AA formation in 100\% of the mice in the saline group and 50\% in the BM-MSCs treatment group $(P<0.05)$. A significant decrease of aortic diameter was observed in the BM-MSCs treatment group at ascending and infrarenal levels, which was associated with decreased macrophage infiltration and suppressed activities of MMP-2 and MMP-9 in aortic tissues, as well as a preservation of elastin content of aortic tissues. In addition, interleukin (IL)-1 $\beta$, IL-6, and monocyte chemotactic protein-1 significantly decreased while insulin-like growth factor-1 and tissue inhibitor of metalloproteinases-2 increased in the aortic tissues of BM-MSCs treatment group.
\end{abstract}

Conclusions: Multiple intravenous administrations of BM-MSCs attenuated the development of Angll-induced AA in $\mathrm{apoE}^{-/-}$mice and may become a promising alternative therapeutic strategy for AA progression.

Keywords: Mesenchymal stem cells, Aortic aneurysm, Cell transplantation, Chronic inflammation, Matrix metalloproteinase

\section{Background}

Aortic aneurysm (AA) is a common life-threatening disease and its prevalence is increasing with the ageing society [1]. For large AAs, which have a high risk of rupture, surgical treatment by open or endovascular repair is generally recommended. However, the great majority of AA is small and below the threshold for immediate surgical repair. Early elective surgical repair of small AA does not provide

\footnotetext{
* Correspondence: ynarita@med.nagoya-u.ac.jp

${ }^{\dagger}$ Equal contributors

Department of Cardiothoracic Surgery, Nagoya University Graduate School of Medicine, 65 Tsurumai-cho, Showa-ku, Nagoya Aichi 466-8550, Japan
}

long term survival advantages $[2,3]$. On the other hand, there are few therapeutic strategies for surgically unsuitable patients who show high risk for surgery. Therefore, the development of a non-surgical therapeutic approach for treating AA is needed. With advances in vascular biology and understanding of the mechanism of AA formation at the cellular and molecular levels, several pharmacological agents, including statins, $\beta$-blockers, ACE-inhibitors, anti-inflammatory agents, and antibiotics, have been reported to limit AA progression in experimental models and some agents have undergone clinical trials $[4,5]$. However, they showed modest benefits in large clinical trials $[5,6]$,
() Biomed Central

(c) 2013 Fu et al.; licensee BioMed Central Ltd. This is an Open Access article distributed under the terms of the Creative Commons Attribution License (http://creativecommons.org/licenses/by/2.0), which permits unrestricted use, distribution, and reproduction in any medium, provided the original work is properly cited. 
and no medicine is currently approved for the prevention of AA progression.

The pathogenesis of AA is characterized by chronic inflammation in the aortic wall with accumulation of macrophages and degradation of extracellular matrix with increased matrix metalloproteinases (MMPs). Infiltrated inflammatory cells such as macrophages, and lymphocytes cause activation of matrix metalloproteinases, particularly MMP-2 and MMP-9, resulting in the degradation of both collagen and its associated collagenous matrix, along with elastin fragmentation and smooth muscle cell (SMCs) apoptosis, which contribute prominently to AA development [7-9]. The positive correlation between inflammatory infiltrates and aneurysmal enlargement [10], as well as regression of established AA by limiting proinflammatory signaling in mice [11], suggest the important role of inflammation in AA pathogenesis.

Mesenchymal stem cells (MSCs) are adult somatic cells that reside in the stroma of solid organs, and have been demonstrated to differentiate into a variety of cell types including: osteoblasts, chondrocytes, and adipocytes [12]. Recently, MSCs have been shown to have antiinflammation effects, and have been applied for treating immune/inflammation associated disorders such as sepsis [13], graft versus host disease [14], and experimental colitis [15]. We previously demonstrated that intraabdominal implantation of BM-MSCs sheet by laparotomy could attenuate the development of angiotensin II (AngII) induced $\mathrm{AA}$ in apolipoprotein E-deficient $\left(\mathrm{apoE}^{-/-}\right)$mice by anti-inflammation [16]. However, this approach requires surgery to deliver BM-MSCs, and may be invasive to patients. Intravenous delivery of BM-MSCs offers an attractive approach, because it is simple, less invasive and is a repeatable administration of a large numbers of cells. The property of BM-MSCs mobilizing or homing into sites of tissue damage or inflammation raises the possibility of intravenous administration of BM-MSCs for treatment of AA [17].

Therefore, in this study, we investigated the effects of intravenous administration of BM-MSCs on AngIIinduced $\mathrm{AA}$ formation in $\mathrm{apoE}^{-/-}$mice.

\section{Methods}

\section{Animal}

$\mathrm{ApoE}^{-/-}$mice (genetic background C57BL/6) were obtained from the Jackson Laboratory (Sacramento, California) and maintained on a regular chow diet under standard conditions. All animal experiments were performed in accordance with the Guide for the Care and Use of Laboratory Animals published by the US National Institutes of Health (NIH publication No. 85-23, revised 1996), and approved by the Animal Care and Use Committee of Nagoya University (protocol No. 24061).
Isolation, culture, and differentiation of bone marrow-derived mesenchymal stem cells

BM-MSCs were isolated from femurs and tibiae of male apoE ${ }^{-/-}$mice (6 to 8 weeks old) and expanded as described [18]. The mesenchymal population was isolated on the basis of its ability to adhere to the culture plate. At $90 \%$ confluence, the cells were trypsinized $(0.05 \%$ Trypsin containing $0.53 \mathrm{mM}$ EDTA-4Na, Invitrogen) and were passaged to $175-\mathrm{cm}^{2}$ flasks. Expansion culture continued up to passages 7-10 were used in all experiments. Cultured BM-MSCs were incubated with the following antibodies, conjugated with phycoerythrin (PE), allophycocyanin (APC) or peridinin chlorophyll proteinCy5.5 (PerCP-Cy5.5) (eBioscience): CD11b, CD31, CD34, CD44, CD45, CD73, CD106, CD117, and Sca-1. Labeled cells were assayed by flow cytometer (FACS Canto II, Becton Dickinson) and analyzed with BD FACSDiva Software and FlowJo (Tree Star Inc.). The capacity to differentiate into osteogenic, adipogenic, and chondrogenic lineages by addition of inductive media was confirmed with chemical staining as performed previously (Additional file 1) [18].

\section{AA model and MSCs transplantation}

Ang II induced aortic aneurysm model in apoE ${ }^{-/-}$mice were used in this study. Male apoE $E^{-/-}$mice (24 to 28 weeks old) were infused with $1000 \mathrm{ng} / \mathrm{kg} / \mathrm{min}$ Ang II (Calbiochem, CA, USA) for 28 days. Ang II was infused using Alzet osmotic pumps (DURECT, Cupertino, Calif, Model 2004). Mice were anesthetized with Isoflurane, delivered using a calibrated vaporizer equipped with an induction chamber and a nose cone, and administered at $2-5 \%$ in $\mathrm{O}_{2}(2 \mathrm{~L} / \mathrm{min})$. It was then decreased to $2 \%$ to maintain anesthesia. Anesthesia was monitored by pinching the toe. Pumps were implanted subcutaneously in the back in the prone position through a small incision that was closed with suture.

The apoE $\mathrm{E}^{-1-}$ male mice were divided randomly into three groups: (1) a sham group (group Sham, $n=10$ ), mice without Ang II infusion or BM-MSCs administration, (2) a control group, mice with Ang II infusion and saline injection (group CONT, $n=10$ ), (3) and a MSCs treatment group, mice with Ang II infusion and multiple BM-MSCs intravenous administration (group MSC4, $n=12$ ). Because the effects of a single intravenous administration of BM-MSCs (group MSC1, $\mathrm{n}=10$ ) were modest in our preliminary experiments (Additional files 2, 3, 4, 5), we established multiple BM-MSCs administration with the same dosage of cells $\left(1 \times 10^{6}\right.$ MSCs in $0.2 \mathrm{ml}$ saline), or $0.2 \mathrm{ml}$ saline was injected weekly into apoE ${ }^{-/-}$mice via tail vein at the time of Alzet osmotic pump implantation. Mice were intravenously administered BM-MSCs or saline four times totally (Figure 1A). 


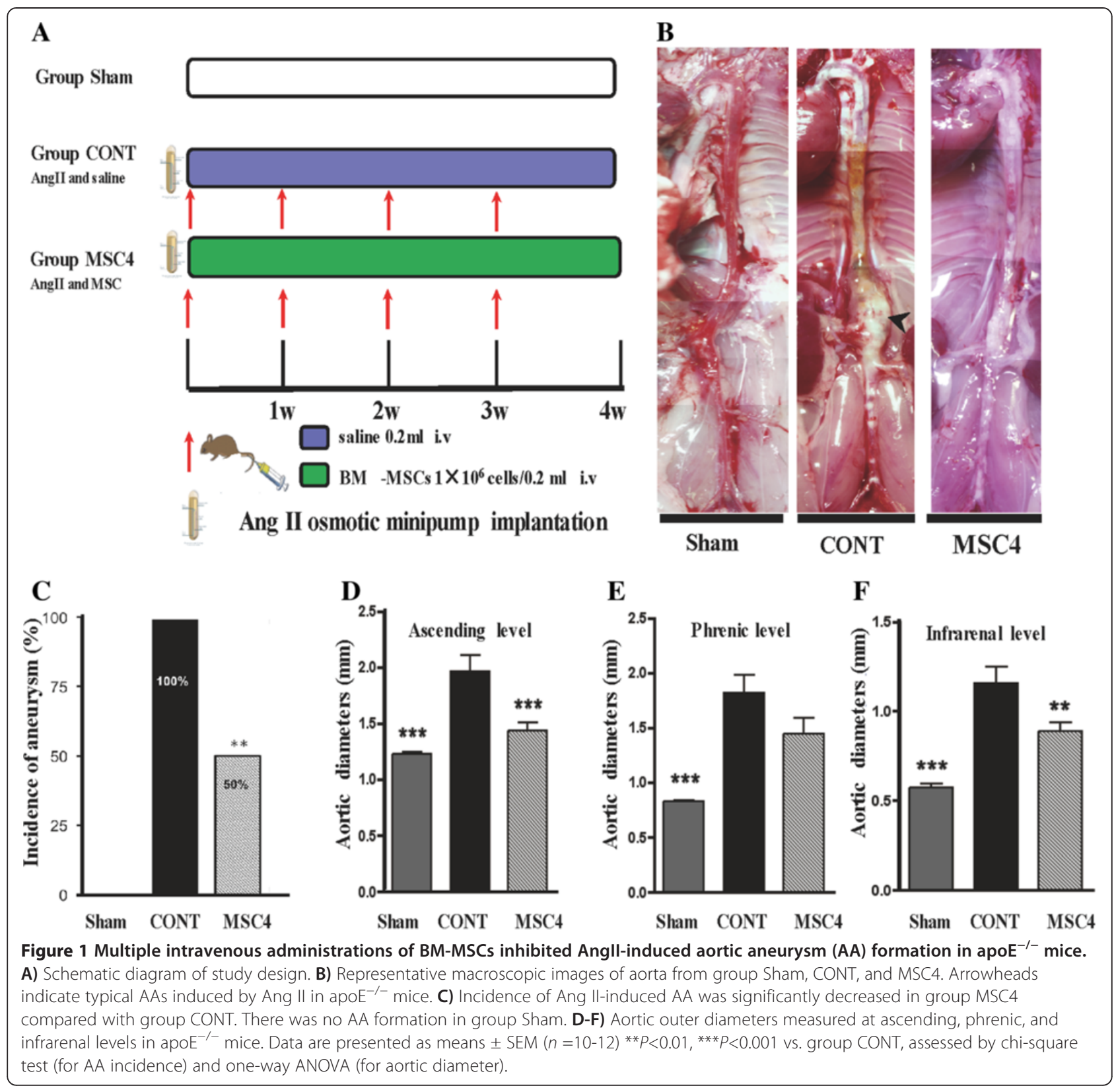

To identify BM-MSCs in the aorta, suspended BMMSCs on the day of transplantation were labeled with fluorescent dyes using a PKH26 red fluorescent cell linker kit (Sigma-Aldrich, St. Louis, MO), as reported previously [19].

Aortic diameter measurement and specimen preparation Twenty-eight days after pump implantation, all animals were euthanized by pentobarbital overdose. The aorta from ascending to the iliac bifurcation was dissected free from the surrounding connective tissue. The outer aortic diameters at the level of the ascending aorta, the abdominal aorta of the phrenic neck, and the abdominal aorta at the infrarenal proximal neck site were obtained with a calibrated ocular grid, as described previously [20]. Images of aorta were recorded with a digital camera and analyzed with Image J software (NIH).

A commonly used clinical standard to diagnose abdominal aortic aneurysm is an increase in aortic diameter of $\approx 50 \%$ [21]. The average diameter of normal suprarenal aorta in naïve control mice is $\approx 0.8 \pm 0.01 \mathrm{~mm}$. We therefore set a threshold of $1.25 \mathrm{~mm}$ as evidence of the incidence of aneurysm formation.

The aorta from the ascending aorta to the iliac bifurcation was then dissected away, and a 2-mm length of suprarenal aorta was cut for histologic examination. The 
remaining aorta was bisected longitudinally for elastin quantification, zymography, and enzyme-linked immunosorbent assay (ELISA).

\section{Measurement of elastin content in aortic tissue}

Elastin was isolated as previously described [22]. The elastin amounts of aortas from apoE ${ }^{-/-}$mice were quantified using a Fastin elastin assay kit (Biocolor, County Antrim, UK) according to the manufacturer's protocol. Briefly, the dissected aortic tissues were weighed and cut into pieces with fine scissors. To convert insoluble elastin to water soluble alpha-elastin, approximately $1 \mathrm{mg}$ (dry weight) of samples were placed with $300 \mu \mathrm{L}$ of $0.25 \mathrm{M}$ oxalic acid into a metal heating block with the thermostat set at $100^{\circ} \mathrm{C}$ for $60 \mathrm{~min}$. The samples were then centrifuged at $3,000 \times \mathrm{g}$ for $10 \mathrm{~min}$ and $250 \mu \mathrm{L}$ of the supernatant was retained in a new container with $250 \mu \mathrm{L}$ of elastin precipitating reagent. The tubes were centrifuged at $10,000 \times \mathrm{g}$ for $10 \mathrm{~min}$ and the supernatants discarded, followed by adding $1.0 \mathrm{~mL}$ of the dye reagent, and were placed in a mechanical shaker at room temperature for $90 \mathrm{~min}$. Subsequently, the tubes were centrifuged at $10,000 \times \mathrm{g}$ for $10 \mathrm{~min}$ and the supernatants discarded. Two-hundred fifty $\mu \mathrm{L}$ of dye dissociation reagent was added to the elastin-bound dye pellet to release the bound dye into solution. Aliquots of each sample $(250 \mu \mathrm{L})$ were transferred to the wells of a 96-well plate and the optical density was measured at $513 \mathrm{~nm}$. Elastin values were standardized to the corresponding dry-weight.

\section{Gelatin zymography}

Gelatin zymography was performed to evaluate MMP-2 and MMP-9 enzymatic activities in aortic tissues as described previously [23]. Briefly, the aortic tissues in vivo were homogenized with a protein extraction buffer containing $20 \mathrm{mM}$ Tris- $\mathrm{HCl}(\mathrm{pH} 7.5)$ and $0.01 \%$ Brij-35 (MP Biomedicals, CA, USA). The protein concentration in each lysate was measured using a BCA assay kit (PIERCE, Rockford, IL, USA). Forty $\mu \mathrm{L}$ of an equal concentration of protein $(0.2 \mathrm{mg} / \mathrm{mL})$ was applied to the samples for electrophoresis, and was detected using a Gelatin Zymography electrophoresis kit (Life Kenkyusho, Yamagata, Japan) according to the manufacturer's protocol. To quantitatively assess the intensity of bands for MMPs quantitatively, densitometric analysis was performed using Digi Print Doc (Bio tools, Gunma, Japan) with imaging Quant TL (GE Healthcare, Bucks, UK).

\section{Histology and immunofluorescence staining}

Suprarenal aortas from each group were embedded in OCT compound (Tissue-Tek, Miles Inc., IN, USA). Specimens were cut into 5-mm cross-sections, and stained with Elastica Van Gieson (EVG) for elastin fibers. For identifying macrophages in the aortic wall in vivo, rat anti-mouse polyclonal antibody against F4/80 (1:100, AbDSerotec, Oxford, UK) was used, and the secondary antibody Alexa, Fluor 488 conjugated anti-rat IgG $(\mathrm{H}+\mathrm{L})$ (1:1,000, Cell Signaling Technology, Boston, MA, USA) was used for detection. Nuclei were stained with 40, 6-diamidino-2-phenyindole, DAPI (Vector Laboratories, Burlingame, CA, USA). Slides were examined with Olympus IX51 microscope and images captured using DP2-BSW software (Olympus, Tokyo, Japan). Quantification of F4/80 staining area was performed by two blinded investigators in 10 randomly selected areas and subsequently averaged using the Image-Pro Plus version 4.1 software (Media Cybernetics, Inc., MD).

\section{Quantitative protein expression of aortic tissue}

The quantitative expression of protein including MMP inhibitors (TIMP-1 and -2), chemokine (MCP-1), cytokines (IL-1ß, IL-6, and TNF- $\alpha$ ), and growth factors (IGF-1 and TGF-ß1) was determined by enzyme-linked immunosorbent assay (ELISA) as described previously [23]. Aortic tissues were homogenized in protein extraction buffer (CytoBusterTM; Novagen, Merck KGaA, Darmstadt, Germany) with $20 \mathrm{mM}$ EDTA (Dojindo, Kumamoto, Japan) and $1 \mathrm{mM}$ PMSF (Thermo, Fisher Scientific, MA, USA). The protein concentration for the lysate was measured using a BCA assay kit (Pierce). An equal concentration of total protein was applied to samples for each plate and detected according to the manufacturer's protocol of each ELISA kit (IGF-1; Mediagnost, Reutlingen, Germany, TGF-ß1, TIMP-1; R\&D Systems, Minneapolis, MN, USA, TIMP-2; RayBiotech, Norcross, GA, USA, IL-1ß, IL-6, TNF- $\alpha$ and MCP-1; Bender MedSystems, Vienna, Austria).

\section{Statistical analyses}

Data analyses were performed with GraphPad Prism for Mac (Version 4, San Diego, CA, USA). Results were expressed as mean \pm SEM. Statistic comparison for the incidence of AA was performed by chi-square test. Multiple comparisons of mean values were performed by a one-way factorial analysis of variance (ANOVA), and unpaired $t$-tests. Statistical significance was defined as $P<0.05$.

\section{Results}

BM-MSCs inhibited the development of AA in Ang Il-infused apoE $^{-/-}$mice

To determine the effects of intravenous administration of BM-MSCs on Ang II-induced AA formation, AngIIinfused apoE ${ }^{-/-}$mice received multiple intravenous administrations of BM-MSCs or saline via tail vein. Figure $1 \mathrm{~B}$ shows representative images of aortas from each group. The incidence of the development of AA in group CONT was $100 \%$, which was significantly decreased 
to $50 \%$ in group MSC4 (Figure 1C). Then, the aortic outer diameter at the ascending, phrenic, and infrarenal level in each group was measured. At those three levels, group CONT mice showed a significantly larger aortic diameter compared with group Sham. Treatment with BM-MSCs resulted in significantly decreased aortic diameters compared with group CONT at the levels of ascending and infrarenal, but not at the phrenic level (Figure 1D-F). These results indicated that AngII infusion for 28 days in apoE ${ }^{-/-}$mice induced AAs and that this process could be effectively inhibited by multiple intravenous administrations of BM-MSCs.

\section{BM-MSCs suppressed aortic elastin degradation in} Angll-infused apoE $^{-/-}$mice

EVG-stained sections from suprarenal aortas of group Sham showed normal wavy elastic lamina structure in the aortas, but sections from group CONT showed disruption of elastic fibers and aneurysm formation. Intravenous administration of MSCs partially maintained the wavy structure of the elastic lamellae (Figure 2A-C). In addition, elastin volume of the aortic tissues was measured. The elastin content of the aorta in group MSC4 was significantly increased compared with group CONT, and showed no significant difference compared with group Sham (group MSC4 vs. group CONT, $39.69 \pm 7.65$ vs $24.80 \pm 2.78, \mu \mathrm{g} / \mathrm{mg}, P<0.01$; group MSC4 vs. group Sham, $39.69 \pm 2.21$ vs. $48.35 \pm 3.28, \mu \mathrm{g} / \mathrm{mg}, P>0.05$; Figure 2D).

\section{BM-MSCs decreased inflammatory response in Angll-infused apoE $^{-/-}$mice}

Immunofluorescence staining demonstrated that F4/80positive macrophages were detected abundantly in the adventitia and media of the suprarenal aortic walls of group CONT. The macrophages infiltration was ameliorated by BM-MSCs administration (Figure $3 \mathrm{~A}-\mathrm{E}$ ). Quantitation of the area of F4/80 staining as a ratio of the DAPI staining area was shown in Figure $3 \mathrm{~J}$.

\section{BM-MSCs suppressed MMP-2 and MMP-9 activity in Angll-infused apoE ${ }^{-/-}$mice}

Gelatin zymography was conducted to evaluate MMP-2 and -9 enzymatic activities in the aortic tissues. A representative zymogram was shown in Figure 4A. Quantitation of the band intensity shows that (pro- and active-)

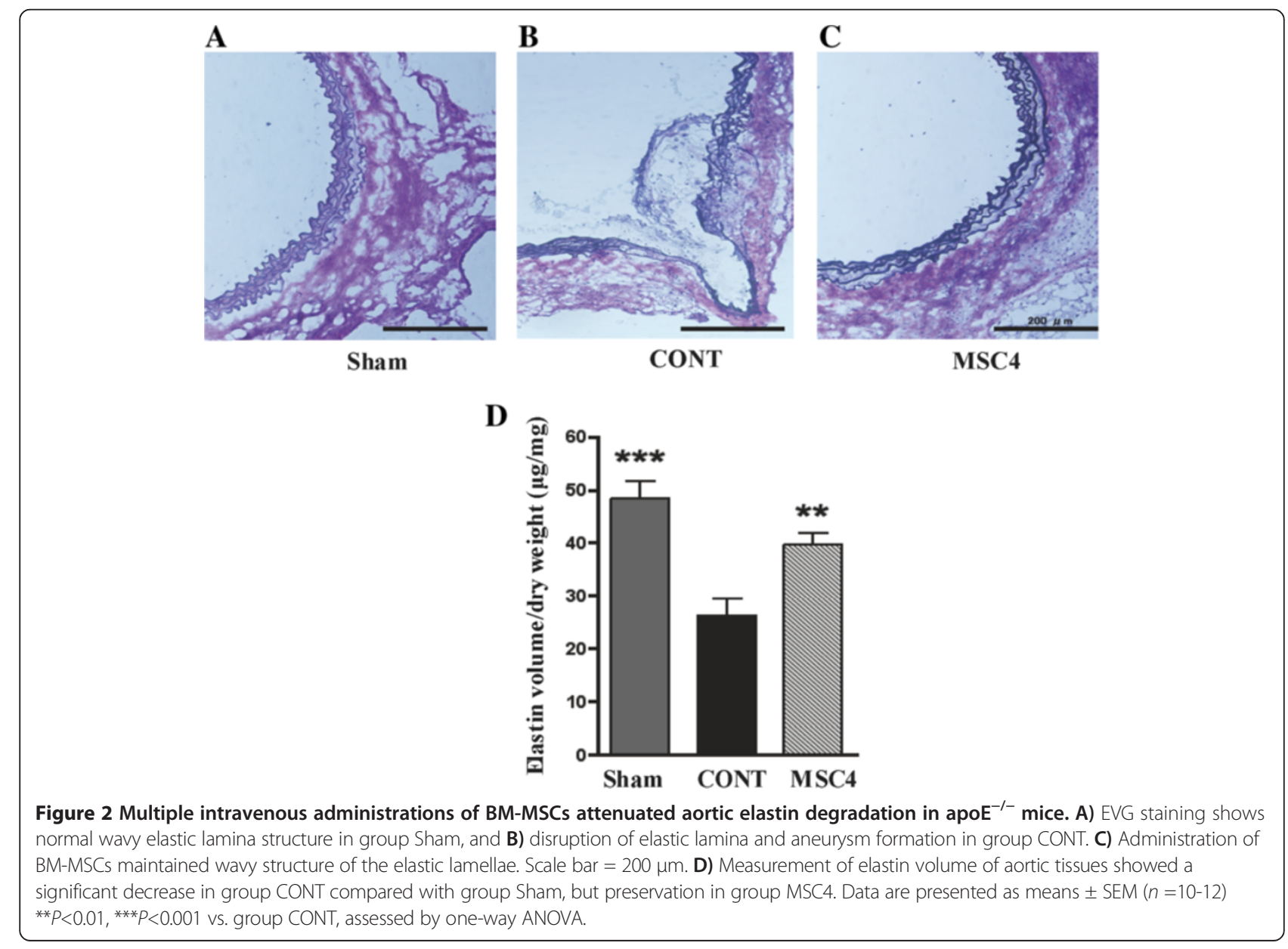



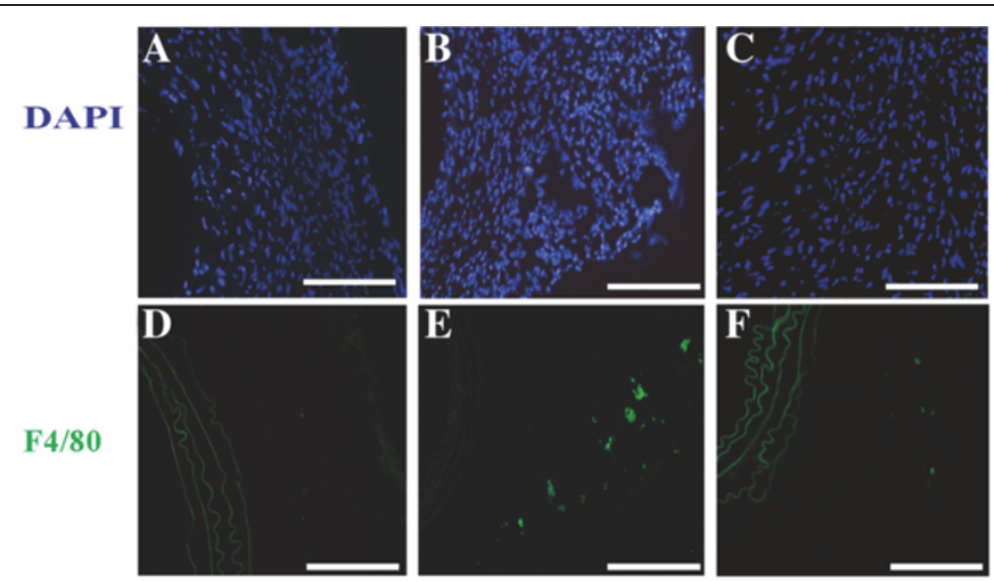

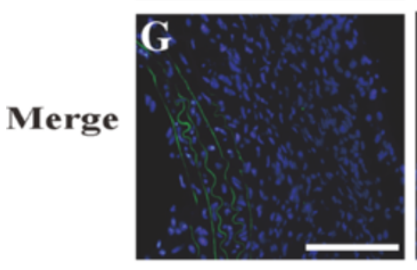

Sham

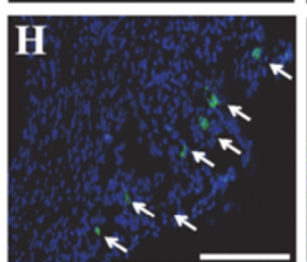

CONT

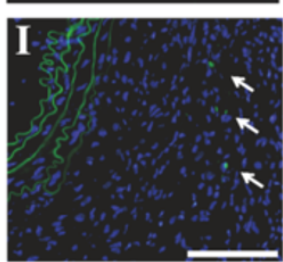

MSC4

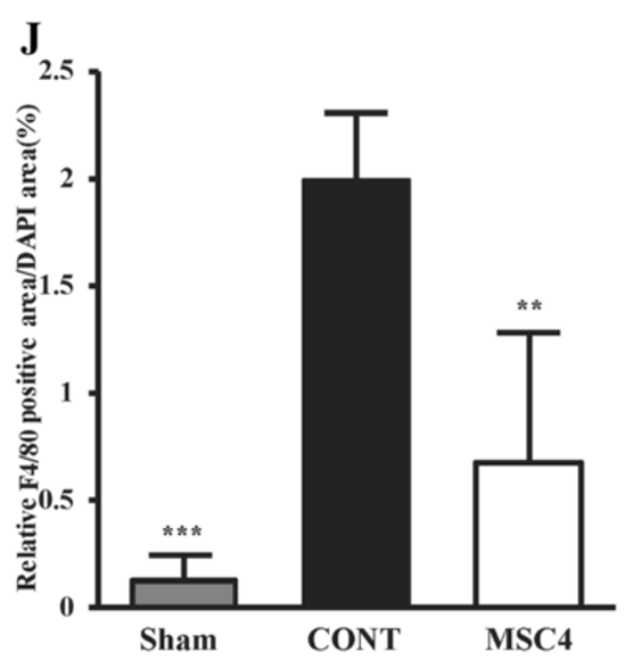

Figure 3 Multiple intravenous administrations of BM-MSCs suppressed macrophage infiltration in aortic tissues. A-I) Representative F4/80 immunofluorescence stained sections of suprarenal aortas from Sham, CONT, and MSC4 groups. Arrowheads indicated F4/80 macrophages. Scale bars $=100 \mu \mathrm{m}$. J) Quantitation of F4/80- positive macrophages area as a ratio of the DAPI staining area. Data are presented as means \pm SEM $(n=10-12)$ ${ }^{* *} P<0.01,{ }^{* * *} P<0.001$ vs. group CONT, assessed by one-way ANOVA.

MMP-2 and (pro- and active-) MMP-9 activities were significantly decreased in group MSC4 compared with group CONT (Figure 4B-E).

\section{BM-MSCs regulated aortic cytokines, chemokine, and} growth factors expression

Protein expression including MMP inhibitors (TIMP-1 and TIMP-2), chemokine (MCP-1), proinflammatory cytokines (IL-1ß, IL-6, and TNF- $\alpha$ ), and growth factors (IGF-1 and TGF-ß1) was evaluated by ELISA. There were no statistical differences in TNF- $\alpha$ expression between group CONT and group MSC4, while expressions of IL-1 $\beta$, IL-6, and MCP-1 that promote inflammatory reaction were significantly decreased in group MSC4 compared with group CONT (Figure 5A-D). At the same time, the expression of IGF-1 and TIMP-2 which promote elastin synthesis were significantly increased in group MSC4 compared with group CONT, though expression of TGF- $\beta 1$ and TIMP-1 showed no significant difference (Figure 5E-H). 

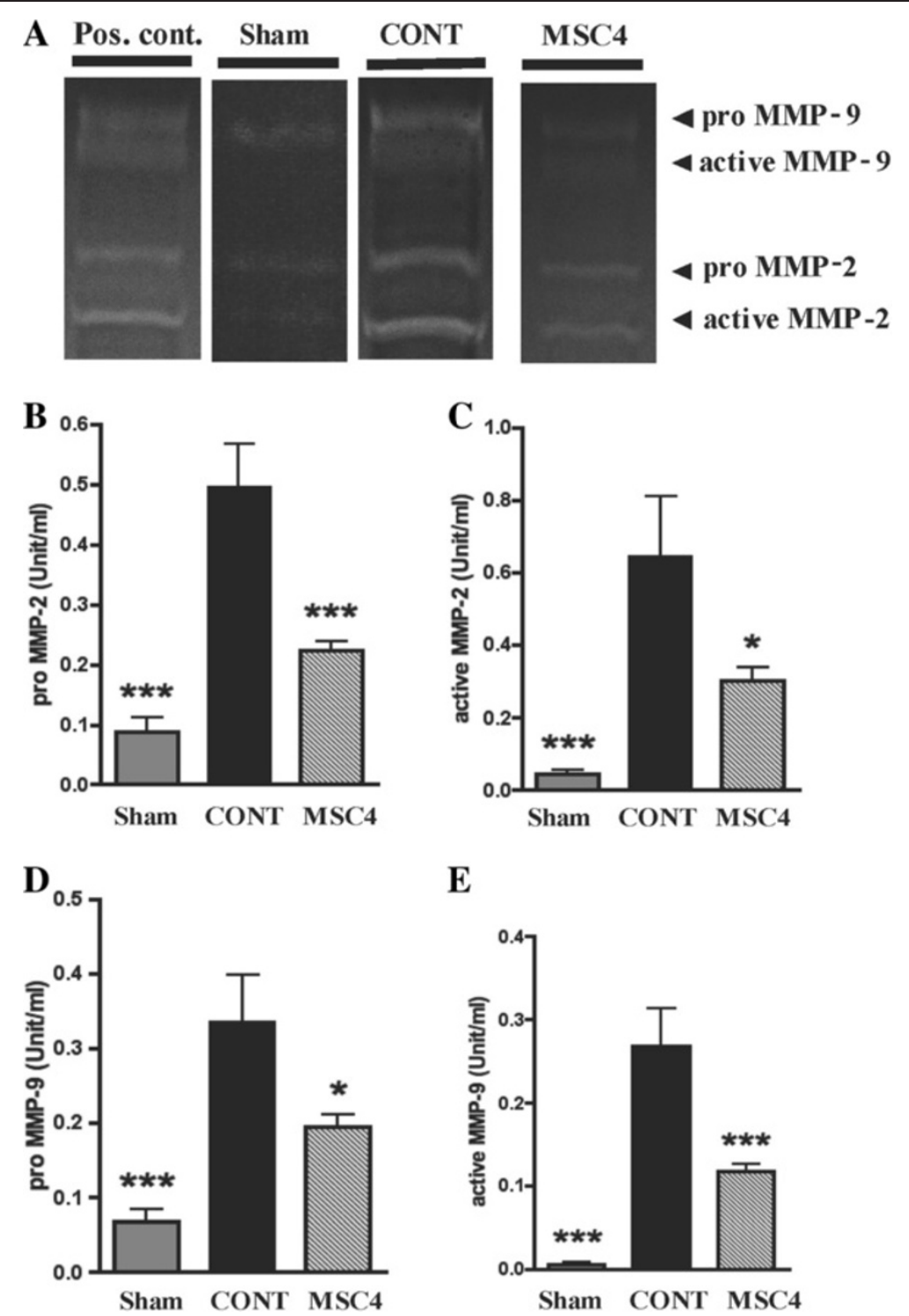

$\mathbf{E}$

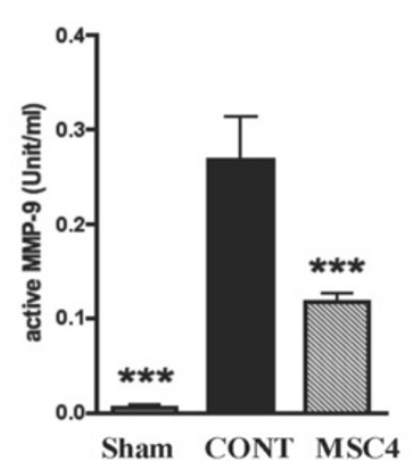

Figure 4 Gelatin zymography of MMPs activities in aortic tissues. A) Gelatin zymography of 4 representative specimens from positive control (from kit), and Sham, CONT, and MSC4 groups. B-E) Zymographic band densities from all tissue samples were quantified by densitometry. Enzyme activities of (pro- and active-) MMP-2 and MMP-9 were significantly decreased in group MSC 4 compared with group CONT. The enzyme activities of MMPs are expressed as a mean \pm SEM $(n=10-12) .{ }^{*} P<0.05$. ${ }^{* *} P<0.001$ vs. group CONT, assessed by one-way ANOVA. MMPs, matrix metalloproteinases.

\section{Cell tracking of transplanted BM-MSCs}

We investigated whether intravenous injected BM-MSCs mobilized into the aortic walls. BM-MSCs were labeled with fluorescent PKH26 and then intravenously injected into the apoE ${ }^{-/-}$mice via tail vein. PKH26 labeled BMMSCs were detected in the media and adventitia of aortas four weeks after operation (Figure 6).

\section{Discussion}

In the present study, we demonstrated that intravenouslyadministered BM-MSCs were capable of engrafting into the aortic wall in Ang II-infused apoE ${ }^{-/-}$mice, and that multiple intravenous administrations of BM-MSCs could effectively: (1) reduce the incidence of AA, (2) suppress both inflammatory reaction and elastin degradation in aortic tissues, and (3) inhibit MMP-2 and MMP-9 activities in the aortic tissues. Here, for the first time, we showed that multiple intravenous administrations of BM-MSCs were effective for prevention of Ang II-induced $\mathrm{AA}$ in $\mathrm{apoE}^{-/-}$mice.

Ang II-induced AA in apoE ${ }^{-/-}$mice provides a model that resembles human AA. Ang II promotes vascular inflammation characterized by macrophage infiltration in the vascular wall [24,25]. Macrophages are a major 

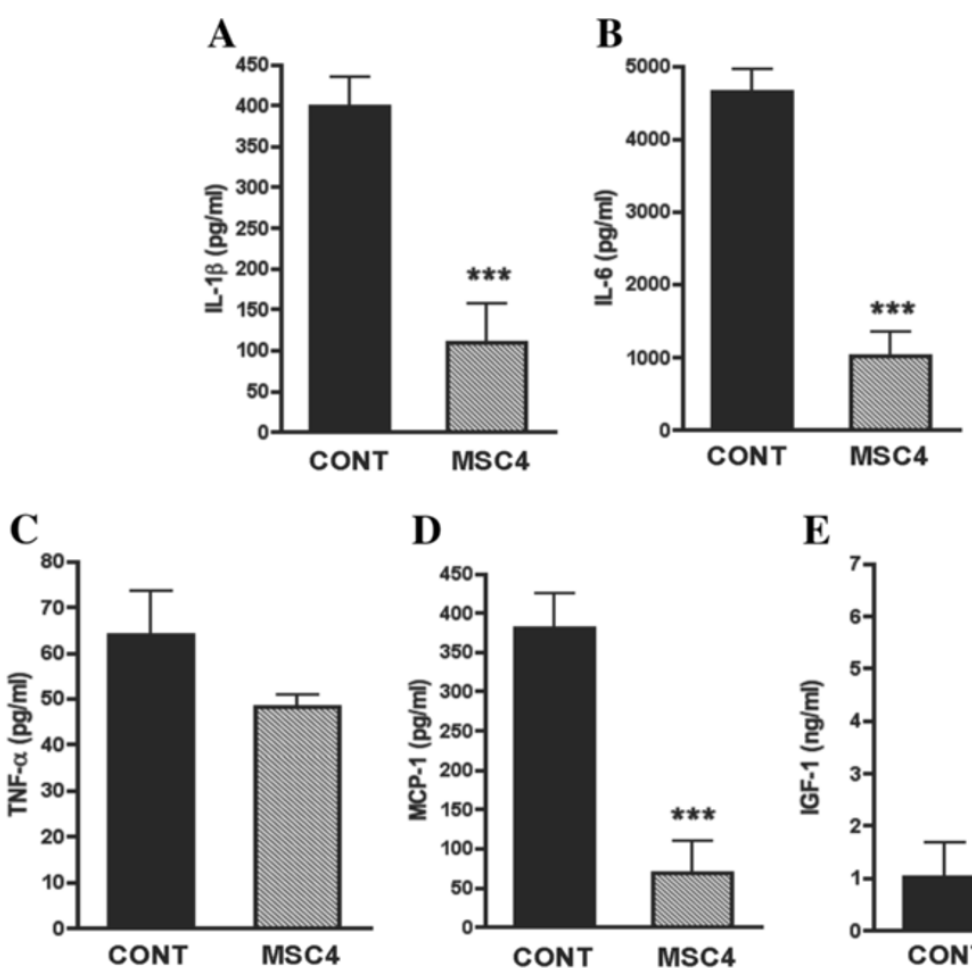

D

$\mathbf{E}$
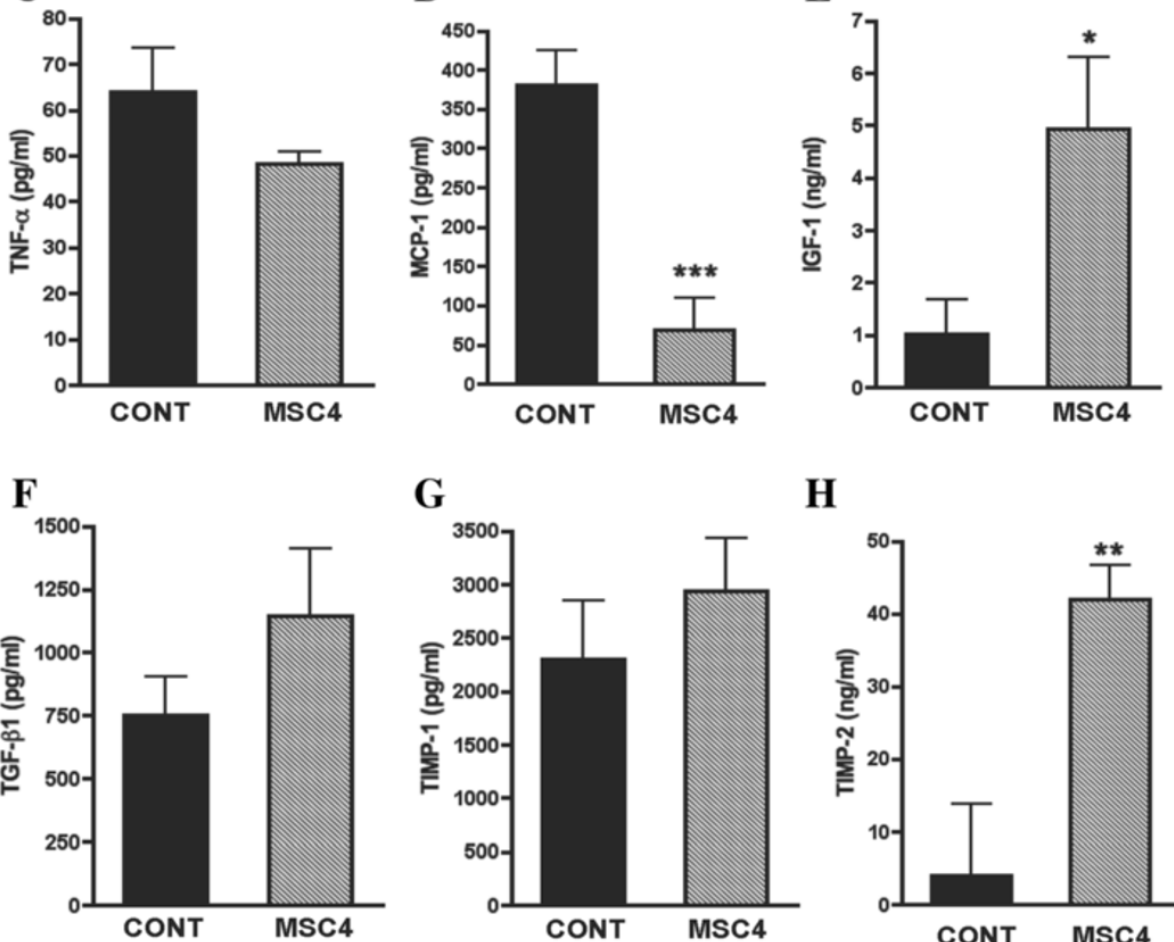

G

$\mathbf{H}$
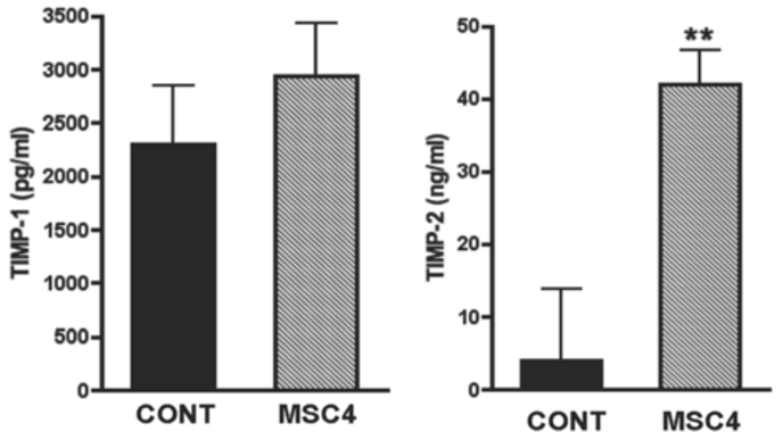

Figure 5 ELISA analyses of inflammatory cytokines (IL-1 $\beta$, IL-6, and TNF- $\alpha$ ), chemokine (MCP-1), tissue inhibitor of metalloproteinases (TIMP-1 and TIMP-2), and growth factors (IGF-1 and TGF- $\beta 1$ ) in aortic tissues 4 weeks after operation. Intravenously administered BM-MSCS reduced IL-1 $\beta$ (A), IL-6 (B), and MCP-1 (D) but did not significantly alter expression of TNF-a (C). BM-MSCs also increased expressions of IGF-1 (E), and TIMP-2 (H) but did not alter expressions of TGF- $\beta 1$ (F) and TIMP-1 (G). All data are presented as mean \pm SEM $(n=10-12) .{ }^{*} P<0.05$, ** $P<0.01$, and ${ }^{* * *} P<0.001$ vs. group CONT, assessed by unpaired $t$-test. IL, interleukin; TNF, tumor necrosis factor; MCP, monocyte chemotactant protein; TGF- $\beta$, transforming growth factor $\beta$; IGF-1, insulin-like growth factor; TIMP, tissue inhibitor of metalloproteinase.

source of proteolytic enzymes like MMPs, which can degrade the extracellular matrix and impair the structural integrity of the vascular wall, leading to AA formation [25]. On the other hand, it has been reported that activated macrophages produce a number of proapoptotic mediators, which result in apoptosis of SMCs [26]. Thus, vascular inflammation, which triggers both vascular wall proteolysis and SMCs apoptosis, could result in an imbalance between extracellular matrix degradation and synthesis, favoring tissue destruction and AA formation. Accumulating evidence indicates that anti-inflammation is a promising therapeutic strategy for AA [4]. MSCs reportedly have anti-inflammation activities [27]. This anti-inflammatory effect of MSCs could inhibit both the proteolytic and proapoptotic pathways, thus restoring the balance between matrix synthesis and degradation, thereby improving tissue repair.

We previously reported that intra-abdominal implantation of BM-MSCs sheets by laparotomy inhibited the development of Ang II-induced aortic aneurysm in apo: ${ }^{-/-}$mice by anti-inflammation and elastin preservation [16]. However, BM-MSCs implantation by laparotomy 


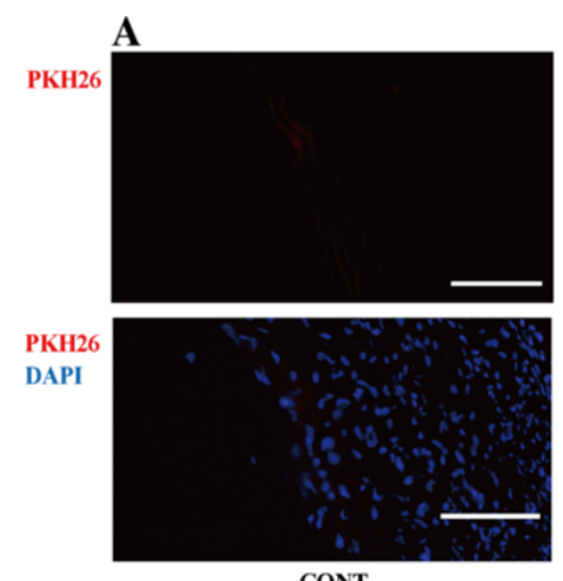

CONT
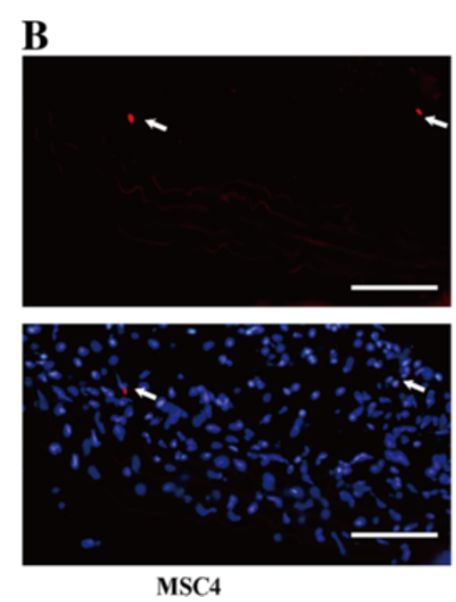

Figure 6 Tracking of transplanted PKH26 labeled BM-MSCs in the aortic walls. A) Representative aortic sections from group CONT. B) Representative aortic sections from group MSC4. Four weeks after operation, PKH26-positive BM-MSCs were mainly observed in the adventitia of aorta in group MSC4. Arrows point to sites of BM-MSC. At least three random aortic cross sections per mouse were chosen for evaluation. PKH26 (red), DAPI (blue), Scale bars $=100 \mu \mathrm{m}$.

is an invasive approach; an alternative delivery approach is needed. Numerous experimental studies have shown that intravenous delivery of MSCs is an effective approach for treatment of a variety of diseases such as myocardial infarction [28], stroke [29], lung injury [30], and diabetes mellitus [31]. Moreover, it is considered a suitable route for translation into clinical application, due to its low invasiveness. In the present study, we investigated the effects of intravenous administrations of BM-MSCs on AngII- induced AA formation in apoE ${ }^{-/-}$mice. In our preliminary experiments we found that the effects of single intravenous administration of BM-MSCs were modest (data was shown in additional figures), then we focused on multiple intravenous administrations of BM-MSCs. Our results demonstrated that multiple intravenous administrations of BM-MSCs significantly reduced the incidence of Ang II-induced AA in apoE ${ }^{-/-}$mice.

Consisted with our previous study, we found that multiple intravenous administrated BM-MSCs suppressed infiltration of macrophages and activities of MMPs in the aortic walls. BM-MSCs also markedly decreased proinflammatory cytokines secretions including IL-1 $\beta$, IL-6, and MCP-1, while increasing growth factor expressions like IGF-1 and TIMP-2, which promote elastin synthesis. These results suggested that the effects of multiple intravenous administrated BM-MSCs on Ang II-induced AA in apoE ${ }^{-/-}$mice may be associated with anti-inflammatory actions.

It should be noted that in this study multiple intravenous administrations of BM-MSCs effectively inhibited development of AngII-induced AA in apoE ${ }^{-/-}$mice, while single intravenous administration of BM-MSCs showed modest effects. We presumed that the timing and cell dose of BMMSCs might account for the different results. BM-MSCs were shown to be able to migrate into sites of inflammation or injury when transplanted locally or systemically [32], which was believed to be mediated by chemotactic proteins such as MCP-1, and IL-8 secreted from injured or inflammatory tissues [33]. The timing of single BM-MSCs injection in this study was just after pump implantation, and at that time aortic inflammation did not occur. On the other hand, we intravenously administrated $4 \times 10^{6}$ BM-MSCs for each mouse in multiple injection group while $1 \times 10^{6}$ in single injection group. The different cell dose may affect the strength of anti-inflammatory effects of BM-MSCs. The appropriate timing and cell dose for intravenous administrations of BM-MSCs treatment of AA remain unclear. Further studies are currently under investigation by our group.

There are several limitations to the present study. First, the BM-MSCs population used in this experiment may be mixed, rather than limited to BM-MSCs, although cell surface markers of cultured cells were consistent with those previously reported [18]. Second, although we observed the effects of multiple intravenous administrations of BM-MSCs 4 weeks after operation, the longterm effects remain unclear, and further experiment is needed. Third, we used a model of Ang II-induced AA in apoE $^{-/-}$mice, further experiments using other AA models are needed to confirm the effects of multiple intravenous administrations of BM-MSCs.

\section{Conclusions}

Multiple intravenous administrations of BM-MSCs were effective to suppress inflammatory reactions in Ang IIinfused apoE ${ }^{-/-}$mice, and inhibit the development of AAs. It may therefore serve as a new therapeutic strategy for patients with AA. 


\section{Additional files}

Additional file 1: Figure 1. Characterization of BM-MSCs. A) Morphology of BM-MSC. Scale bar=100 $\mu \mathrm{m}$. B-D) Multipotency of BM-MSCs. BM-MSCs differentiated into osteocytes (B), adipocytes (C), and chondrocytes (D). Scale bars $=100 \mu \mathrm{m}$. E) Flow cytometric analysis of BM-MSCs.

Additional file 2: Figure 2. Single intravenous administration of BM-MSCS did not inhibit Ang II-induced aortic aneurysm formation in apoE ${ }^{-/-}$ mice. A) Incidence of Aortic aneurysm. B-D) Aortic outer diameters measured at ascending, phrenic, and infrarenal levels in $a p o E^{-1-}$ mice. Data are presented as means $\pm \operatorname{SEM}(n=10-12){ }^{* *} P<0.01,{ }^{* * *} P<0.001$ vs. group CONT, assessed by chi-square test (for AA incidence) and one-way ANOVA (for aortic diameter)

Additional file 3: Figure 3. Single intravenous administration of BM-MSCs did not attenuate aortic elastin degradation in apoE ${ }^{-/-}$mice. A) EVG staining of suprarenal aortas and B) elastin volume of aortic tissues. Data are presented as means \pm SEM $(n=10-12){ }^{* *} P<0.001$ vs. group CONT, assessed by one-way ANOVA.

Additional file 4: Figure 4. Single intravenous administration of BM-MSCs did not suppress macrophages infiltration in aortic tissues. Representative F4/80 immunohistochemical (A-I) stained sections of suprarenal aortas from Groups Sham, CONT, and MSC1. Scale bars=100 $\mu \mathrm{m}$. J) Quantitation of F4/80-positive macrophages. Data are presented as means \pm SEM ( $n=10-12)$ ${ }^{*} P<0.01,{ }^{* *} P<0.001$ vs. group CONT, assessed by one-way ANOVA

Additional file 5: Figure 5. Gelatin zymography of MMPs activities in aortic tissues. (A-D) Zymographic band densities were quantified by densitometry. Enzyme activities (pro- and active-) of MMP-2 and MMP-9 are expressed as a mean \pm SEM $(n=10-12)$. ${ }^{* *} P<0.001$ vs. group CONT assessed by one-way ANOVA. MMPs, matrix metalloproteinases.

\section{Competing interests}

The authors declare that they have no competing interests.

\section{Authors' contributions}

$X F, A Y$, and $Y N$ designed the experiment, interpreted results. XF drafted manuscript. XF and AY performed experiments. YN, $\mathrm{HO}, \mathrm{YU}$, and $\mathrm{AU}$ made critical revision to manuscript. All authors have read and approved the final manuscript.

\section{Acknowledgements}

The authors wish to thank the Division for Medical Research Engineering, Nagoya University Graduate School of Medicine, for usage of the FACS Canto II and Criomicrotome and a scholarship from the China Scholarship Council to Xian-ming Fu. This study was supported in part by a Grant-in-Aid for Science Research (No. 23791566) from the Ministry of Education, Culture, Sports, Science and Technology of Japan, and the Japan Vascular Disease Research Foundation.

Received: 12 May 2013 Accepted: 17 July 2013

Published: 22 July 2013

\section{References}

1. Powell JT, Sweeting MJ, Brown LC, Gotensparre SM, Fowkes FG, Thompson SG: Systematic review and meta-analysis of growth rates of small abdominal aortic aneurysms. Br J Surg 2011, 98:609-618.

2. UK Small Aneurysm Trial Participants: Mortality results for randomized controlled trial of early elective surgery or ultrasonographic surveillance for small abdominal aortic aneurysms: the UK Small Aneurysm Trial Participants. Lancet 1998, 352:1649-1655.

3. Lederle FA, Wilson SE, Johnson GR, Reinke DB, Littooy FN, Acher CW, Ballard DJ, Messina LM, Gordon IL, Chute EP, et al: Immediate repair compared with surveillance of small abdominal aortic aneurysms. N Engl J Med 2002, 346:1437-1444.

4. Miyake T, Morishita R: Pharmacological treatment of abdominal aortic aneurysm. Cardiovasc Res 2009, 83:436-443.

5. Baxter BT, Terrin MC, Dalman RL: Medical management of small abdominal aortic aneurysms. Circulation 2008, 117:1883-1889.

6. Lindholt JS, Henneberg EW, Juul S, Fasting H: Impaired results of a randomised double blinded clinical trial of propranolol versus placebo on the expansion rate of small abdominal aortic aneurysms. Int Angiol 1999, 18:52-57.

7. Petersen E, Gineitis A, Wagberg F, Angquist KA: Activity of matrix metalloproteinase-2 and -9 in abdominal aortic aneurysms. Relation to size and rupture. Eur J Vasc Endovasc Surg 2000, 20:457-461.

8. Crowther M, Goodall S, Jones JL, Bell PR, Thompson MM: Increased matrix metalloproteinase 2 expression in vascular smooth muscle cells cultured from abdominal aortic aneurysms. J Vasc Surg 2000, 32:575-583.

9. Freestone T, Turner RJ, Coady A, Higman DJ, Greenhalgh RM, Powell JT: Inflammation and matrix metalloproteinases in the enlarging abdominal aortic aneurysm. Arterioscler Thromb Vasc Biol 1995, 15:1145-1151.

10. Anidjar S, Dobrin PB, Eichorst M, Graham GP, Chejfec G: Correlation of inflammatory infiltrate with the enlargement of experimental aortic aneurysms. J Vasc Surg 1992, 16:139-147.

11. Aoki H, Yoshimura K, Matsuzaki M: Turning back the clock: regression of abdominal aortic aneurysms via pharmacotherapy. J Mol Med (Berl) 2007, 85:1077-1088

12. Pittenger MF, Mackay AM, Beck SC, Jaiswal RK, Douglas R, Mosca JD, Moorman MA, Simonetti DW, Craig S, Marshak DR: Multilineage potential of adult human mesenchymal stem cells. Science 1999, 284:143-147.

13. Nemeth K, Leelahavanichkul A, Yuen PS, Mayer B, Parmelee A, Doi K, Robey PG, Leelahavanichkul K, Koller BH, Brown JM, et al: Bone marrow stromal cells attenuate sepsis via prostaglandin $\mathrm{E}(2)$-dependent reprogramming of host macrophages to increase their interleukin-10 production. Nat Med 2009, 15:42-49.

14. Le Blanc K, Rasmusson I, Sundberg B, Gotherstrom C, Hassan M, Uzunel M, Ringden $\mathrm{O}$ : Treatment of severe acute graft-versus-host disease with third party haploidentical mesenchymal stem cells. Lancet 2004, 363:1439-1441.

15. Hayashi Y, Tsuji S, Tsujii M, Nishida T, Ishii S, lijima H, Nakamura T, Eguchi H, Miyoshi E, Hayashi N, Kawano S: Topical implantation of mesenchymal stem cells has beneficial effects on healing of experimental colitis in rats. J Pharmacol Exp Ther 2008, 326:523-531.

16. Hashizume R, Yamawaki-Ogata A, Ueda Y, Wagner WR, Narita Y: Mesenchymal stem cells attenuate angiotensin II-induced aortic aneurysm growth in apolipoprotein E-deficient mice. J Vasc Surg 2011 54:1743-1752.

17. Lapidot T, Petit I: Current understanding of stem cell mobilization: the roles of chemokines, proteolytic enzymes, adhesion molecules, cytokines, and stromal cells. Exp Hematol 2002, 30:973-981.

18. Zhu H, Guo ZK, Jiang XX, Li H, Wang XY, Yao HY, Zhang Y, Mao N: A protocol for isolation and culture of mesenchymal stem cells from mouse compact bone. Nat Protoc 2009, 5:550-560.

19. Wang T, Tang W, Sun S, Ristagno G, Huang Z, Weil MH: Intravenous infusion of bone marrow mesenchymal stem cells improves myocardial function in a rat model of myocardial ischemia. Crit Care Med 2007, 35:2587-2593.

20. Bartoli MA, Parodi FE, Chu J, Pagano MB, Mao D, Baxter BT, Buckley C, Ennis TL, Thompson RW: Localized administration of doxycycline suppresses aortic dilatation in an experimental mouse model of abdominal aortic aneurysm. Ann Vasc Surg 2006, 20:228-236.

21. Johnston KW, Rutherford RB, Tilson MD, Shah DM, Hollier L, Stanley JC: Suggested standards for reporting on arterial aneurysms: subcommittee on reporting standards for arterial aneurysms, Ad Hoc committee on reporting standards, society for vascular surgery and North American chapter, international society for Cardiovascular Surgery. J Vasc Surg 1991, 13:452-458.

22. Ross $R$, Bornstein $P$ : The elastic fiber: I The separation and partial characterization of its macromolecular components. J Cell Biol 1969, 40:366-381.

23. Yamawaki-Ogata A, Hashizume R, Satake M, Kaneko H, Mizutani S, Moritan T, Ueda Y, Narita Y: A doxycycline loaded, controlled-release, biodegradable fiber for the treatment of aortic aneurysms. Biomaterials 2010, 31:9554-9564.

24. Daugherty A, Cassis LA: Mechanisms of abdominal aortic aneurysm formation. Curr Atheroscler Rep 2002, 4:222-227.

25. Daugherty A, Manning MW, Cassis LA: Angiotensin II promotes atherosclerotic lesions and aneurysms in apolipoprotein E-deficient mice. J Clin Invest 2000, 105:1605-1612.

26. Henderson EL, Geng YJ, Sukhova GK, Whittemore AD, Knox J, Libby P: Death of smooth muscle cells and expression of mediators of apoptosis by $\mathrm{T}$ lymphocytes in human abdominal aortic aneurysms. Circulation 1999, 99:96-104. 
27. Prockop DJ, Oh JY: Mesenchymal stem/stromal cells (MSCs): role as guardians of inflammation. Mol Ther 2012, 20:14-20,

28. Price MJ, Chou CC, Frantzen M, Miyamoto T, Kar S, Lee S, Shah PK, Martin BJ, Lill M, Forrester JS, et al: Intravenous mesenchymal stem cell therapy early after reperfused acute myocardial infarction improves left ventricular function and alters electrophysiologic properties. Int J Cardiol 2006, 111:231-239.

29. Bang OY, Lee JS, Lee PH, Lee G: Autologous mesenchymal stem cell transplantation in stroke patients. Ann Neurol 2005, 57:874-882.

30. Aslam M, Baveja R, Liang OD, Fernandez-Gonzalez A, Lee C, Mitsialis SA, Kourembanas $\mathrm{S}$ : Bone marrow stromal cells attenuate lung injury in a murine model of neonatal chronic lung disease. Am J Respir Crit Care Med 2009, 180:1122-1130.

31. Ho JH, Tseng TC, Ma WH, Ong WK, Chen YF, Chen MH, Lin MW, Hong CY, Lee OK: Multiple intravenous transplantations of mesenchymal stem cells effectively restore long-term blood glucose homeostasis by hepatic engraftment and beta-cell differentiation in streptozocin-induced diabetic mice. Cell Transplant 2011, 21:997-1009.

32. Ji JF, He BP, Dheen ST, Tay SS: Interactions of chemokines and chemokine receptors mediate the migration of mesenchymal stem cells to the impaired site in the brain after hypoglossal nerve injury. Stem Cells 2004, 22:415-427.

33. Wang L, Li Y, Chen X, Chen J, Gautam SC, Xu Y, Chopp M: MCP-1, MIP-1, IL-8 and ischemic cerebral tissue enhance human bone marrow stromal cell migration in interface culture. Hematology 2002, 7:113-117.

doi:10.1186/1479-5876-11-175

Cite this article as: Fu et al:: Intravenous administration of mesenchymal stem cells prevents angiotensin II-induced aortic aneurysm formation in apolipoprotein E-deficient mouse. Journal of Translational Medicine 2013 11:175.

\section{Submit your next manuscript to BioMed Central and take full advantage of:}

- Convenient online submission

- Thorough peer review

- No space constraints or color figure charges

- Immediate publication on acceptance

- Inclusion in PubMed, CAS, Scopus and Google Scholar

- Research which is freely available for redistribution 